\title{
A INFLUÊNCIA DO MEIO SOBRE O EMPREENDEDORIMSO A PARTIR DAS DIMENSÕES NORMATIVA, REGULATIVA E COGNITIVA
}

\section{THE INFLUENCE OF ENVIRONMENT ON ENTREPRENEURSHIP FROM THE NORMATIVE, REGULATORY AND COGNITIVE DIMENSIONS}

William José Borges

Professor no Instituto Federal de Santa Catarina - Doutorando em Administração (UFSC), Coordenador de

Pesquisa e Inovação do Campus Geraldo Werninghaus.

Jaraguá do Sul, SC, Brasil

E-mail: willian.borges@ifsc.edu.br

Tiago Savi Mondo

Professor no Instituto Federal de Santa Catarina - Doutor em Administração.

Florianópolis, SC, Brasil

E-mail: tiago.mondo@ifsc.edu.br

Hilka Pelizza Vier Machado

Professora da Universidade do Oeste de Santa Catarina (UNOESC), junto ao Programa de Pós Graduação em Administração. Professora Aposentada da Universidade Estadual de Maringá, Estado do Paraná. Atua como consultora Ad Hoc junto à Fundações de Amparo à Pesquisa de Estados brasileiros, bem como junto ao CNPq e à CAPES.

Maringá, PR, Brasil

E-mail: hilkavier@yahoo.com.br

\section{RESUMO}

A relação entre empreendedorismo e meio é consequência de uma interação de teorias, tornando possível criar relações entre o desenvolvimento empreendedor e o ambiente que o propulsiona. Assim o objetivo deste trabalho é identificar como estudos que consideram $o$ meio e como atividades empreendedoras são influenciadas, levando-se em conta os elementos normativo, regulativo e cognitivo abordados por Busenitz et al. (2000). A pesquisa é considerada descritiva-interpretativa de levantamento teórico. Os principais resultados, indicam grande influência entre as dimensões normativa, regulativa e cognitiva, e uma complementaridade desses elementos quando observados a longo prazo, o qual é visto por meio de informações transmitidas através da interatividade entre os agentes e instituições de uma região. As interações dos agentes com os elementos do meio acarretam em uma sinergia, pois a concentração de elementos pertencentes às três dimensões, simultaneamente, cria uma região denominada "ambiente empreendedor" capaz de contribuir com o fomento do empreendedorismo.

Palavras-chave: Empreendedorismo. Meio. Normatização. Regulação e Cognição.

Data de submissão: 19 de março de 2015.

\section{ABSTRACT}

The relationship between entrepreneurship and context is the result of an interaction of theories, making it possible to create relationships between entrepreneurial development and the environment that propels. So the aim of this study is to identify how studies that consider the environment and how entrepreneurial activities are influenced, taking into account the normative, regulative and cognitive elements addressed by Busenitz et al. (2000). The research is considered descriptive-interpretive theoretical survey. The main results indicate great influence among the normative dimensions, regulative and cognitive, and complementarity of these elements when viewed in the long term, which is seen through information transmitted over the interaction between the agents and institutions of a region. The interactions of the agents with the elements carry through in a synergy, because the concentration of elements belonging to the three dimensions simultaneously creates a region called the "entrepreneurial environment" able to contribute to the promotion of entrepreneurship.

Keywords: Entrepreneurship. Environment. Standardization. Regulation and Cognition.

Data de aprovação: 27 de fevereiro de 2016. 


\section{INTRODUÇÃO}

O empreendedorismo mantém vínculo com vários outros temas amplos, como o ambiente e o desenvolvimento de regiões, aparentando ser um campo de pesquisa caracterizado pela sua complexidade, mas também pela amplitude de suas possibilidades de desenvolvimento científico. A relação entre empreendedorismo e ambiente regional é consequência dessa interação das teorias, tornando possível criar relações entre o desenvolvimento empreendedor e o ambiente que o propulsiona.

A busca por relações capazes de compreender como o meio pode influenciar o desenvolvimento empreendedor tem sido uma preocupação nos últimos anos (KURATKO; HODGETTS, 2001). Os elementos do meio poderiam, a partir de estudos acadêmicos, fornecer informações úteis para explorar uma variedade de questões sobre as diferenças entre os empreendedores e seus respectivos ambientes. Esse ambiente é capaz de fornecer dados que contribuem para traçar o perfil de cada região, e assim compreender as diferenças quanto às taxas de desenvolvimento, taxa de inovação, criação de novas empresas, entre outras características.

Estudos desenvolvidos no campo do empreendedorismo sobre as características pessoais e experiências de vida de empresários, a identificação de oportunidades no mercado, os fatores que estimulam o empreendedorismo nas empresas, foram relevantes para fundamentar os estudos do presente. Conforme aponta Taylor (2006), há um número crescente de pesquisadores como Armington e Acs (2002), Feldman (2001) e Lichtenstein e Lyons (2001) escrevendo a respeito do ambiente como fator de influência do desempenho empreendedor. Portanto, estudos dessa dimensão são capazes de munir os empreendedores com informações criando condições favoráveis para atuar no mercado.

Assim, o objetivo deste trabalho é identificar como estudos contemporâneos consideram o meio e como atividades empreendedoras são influenciadas, levando-se em conta os elementos normativo, regulativo e cognitivo, a fim de identificar os aspectos do ambiente que influenciam a atividade empreendedora. As dimensões normativa, regulativa e cognitiva foram desenvolvidas Busenitz et al. (2000, p. 996) a fim de identificar como políticas governamentais, conhecimento social e sistemas de valores poderiam afetar as atividades de um negócio.

A presente pesquisa pode ser delineada como um ensaio teórico, marcadamente de cunho descritivo e interpretativo. O estudo caracteriza-se por ser de natureza qualitativa, haja vista que, no entendimento de vários autores, como Haguette (2001), as pesquisas qualitativas são consistentes em situações que envolvem estudos teóricos.

Foi realizado um levantamento de estudos dentre os principais journals e revistas da área de empreendedorismo: Journal of Management Studies, Journal of Small Business and Enterprise Development, Journal of Small Business and Entrepreneurship, Journal of Economic Perspectives, Journal of Business Venturing, Strategic Management Journal, Entrepreneurship Theory and Practice, Journal Small Business economics, Academy of Management Journal e Academy of management review. Buscou-se pelos termos: "entrepreneurship", "environment", "cognition", "regulation", "regulation" individualizados em cada uma dessas revistas.

Os artigos foram selecionados em três fases: aderência pelo título, aderência pelo resumo e aderência pelo conteúdo. Após esta análise chegou-se aos artigos utilizados em todo o corpo desta Pesquisa. 
A escolha das dimensões, inicialmente elaboradas por Kostova (1999), ocorreu em função da relevância das classificações para as discussões que envolvem empreendedorismo. Autores como Gartner (1975) e Julien (2010) consideraram em seus trabalhos o meio, mas não se encontram trabalhos teóricos classificando os elementos do meio em dimensões.

Para a melhor compreensão, esse trabalho foi estruturado da seguinte forma: a primeira parte traz algumas definições de meio, explica qual o seu papel e o que se entende pelas dimensões normativa, descritiva e regulativa; em continuidade a próxima seção aborda o capital social, em seguida as influencias das dimensões nos elementos do ambiente e finalmente as considerações finais.

\section{COMPREENDENDO A RELAÇÃO ENTRE O MEIO E DESENVOLVIMENTO EMPREENDEDOR}

Segundo Julien (2010) grande parte dos artigos publicados considera que apenas alguns elementos do ambiente podem fazer a diferença entre as regiões "atrasadas" e "desenvolvidas" no que se refere às atividades empreendedoras. Isso porque enfatizam apenas aspectos como infraestrutura, posições geográficas, recursos naturais, densidade de mercados, entre outros elementos frequentemente utilizados. No entanto é preciso considerar que o meio é mais do que simplesmente um conjunto de fatores que facilitam a obtenção de recursos e competências.

\section{DEFINIÇÕES DE “MEIO”}

O meio corresponde a um conjunto de fatores exógenos determinantes, ou seja, segundo Jensen e Mecking (1976) trata-se de um conjunto de itens que se combinam para formar a massa produtiva. Pode-se entender que o conjunto de fatores exógenos cria condições para o desenvolvimento das atividades empresariais, favorecendo e facilitando o intercâmbio de produtos e informações.

O meio é o ambiente socioeconômico próximo do ator (empreendedor) e da pequena empresa que facilita, ou não, os relacionamentos e que distingue um território do outro (JULIEN, 2010). Assim os regramentos e instituições que circunscrevem esse meio, tais como leis, regulamentos, políticas governamentais, conhecimentos, redes, entre outras, são agentes influenciadores do desenvolvimento das atividades empreendedoras.

Para Kuratko e Hodgetts (2001) o ambiente consiste em variáveis (oportunidades) externas à organização e que podem afetá-la. O sistema considerado na análise é de sistemas abertos em que a organização e o seu ambiente realizam trocas de informações contínuas, podendo ocorrer uma influência mútua. Na mesma linha de raciocínio, Camagni (1991) propôs a compreensão do meio como sendo: "um espaço relacional, um campo de interações sociais, sinergias interpessoais e ações sociais que determinam a capacidade inovadora e o sucesso econômico de locais específicos".

Várias definições abordam o meio como uma construção social do mercado, dentre elas está a definição de Bagnasco (1999 em que o meio é capaz de facilitar os múltiplos laços entre os recursos, competências e compradores.

Para Ratti et al (1997) o meio é compreendido como um misto de conhecimento, técnicas, cultura, capacidades, entre outros fatores que ao serem combinados formam uma sinergia. Sinergia esta capaz 
impulsionar o desenvolvimento para a realização de trocas entre os agentes da região. O seu enfoque é micro-analítico, ou seja, aborda o tema como um conjunto local de recursos.

Quando se fala em ambiente é preciso considerar os seguintes elementos: disponibilidade de capital de risco, a presença de empresários experientes, mão- de-obra tecnicamente qualificada, acessibilidade dos fornecedores, acessibilidade dos clientes ou novos mercados, influências governamentais, proximidade de universidades da disponibilidade de terrenos ou instalações, acessibilidade de transportes, atitude da população da zona, disponibilidade de apoio serviços, condições de vida, a diferenciação profissional e industrial elevada, elevado percentual de imigrantes recentes na população, base industrial de grande porte, as áreas urbanas de maior tamanho, a disponibilidade de recursos financeiros, barreiras à entrada, a rivalidade entre os concorrentes existentes, poder de barganha dos compradores e poder de barganha dos fornecedores (GARTNER, 1975).

Todos os meios podem ser estudados segundo cinco correntes de pesquisa: instituições públicas, estrutura setorial, mão-de-obra, organizações de cooperação e cultura empreendedora. Pessoas-chave e instituições que organizam e estruturam a dinâmica do meio influenciam as suas regiões de forma a obterem resultados satisfatórios para o seu segmento (JULIEN, 2010). Esses resultados, ou seja, a eficácia no desenvolvimento empreendedor pode ser atingida atuando em um meio estruturado de forma complexa. Essa estruturação foi estudada por Casson (1990) e identificada como fator capaz de aumentar a cooperação entre os empreendedores de um país por facilitar soluções de problemas e aumentar a ação social, onde os indivíduos constroem o meio e são influenciados por ele.

A compreensão de meio para esse ensaio teórico segue a mesma linha de pensamento de Julien (2010) em que o meio é interpretado como um ambiente socioeconômico que envolve o empreendedor e as empresas que atuam em uma determinada região. O meio então se torna um fator determinante na identificação e interpretação do desenvolvimento empreendedor de um ambiente.

\section{O PAPEL DO MEIO PARA O EMPREENDEDORISMO}

O meio pode fornecer subsídios que podem impulsionar ou restringir o desenvolvimento empreendedor. Para cada segmento da economia há um conjunto de fatores que são vistos como premissa no ambiente, por exemplo, quando se fala em tecnologia da informação a premissa básica do campo é que existam computadores capazes de processar dados, o mesmo ocorre quando falamos em geração de ideias, pois as pessoas devem ser capazes de "sentir o momento certo" para utilizar suas habilidades quando ocorrer alguma mudança no meio em que operam.

As interações comerciais também são influenciadas pela cultura de uma região, proporcionando condições para impulsionar o empreendedorismo. Os autores Mueller e Thomas (2000) notam que a cultura, dependendo do momento, pode lapidar a cognição humana e atribuir significados e valores capazes de orientar escolhas e comportamentos. Assim, com o desenvolvimento (econômico e social) de uma região, as mudanças fazem parte de uma construção conjunta entre os agentes, deste modo o misto de significados e valores são as ferramentas que irão contribuir com os empreendedores na identificação e interpretação do seu meio. 
De forma complementar, os autores Hisrich e Peters (2004) argumentam que a compreensão da cultura local deve ser uma premissa para os planos do empreendedor, pois exige adaptação aos costumes, comportamentos e ética. O meio também pode dar subsídios para ativar uma ideia empreendedora através do seu financiamento e consequente materialização. Há várias abordagens que exploram o financiamento empreendedor, alguns autores alocam a responsabilidade para o governo e outros para a rede de relacionamento do empreendedor com o seu meio.

O financiamento, como proposto por Julien (2010) explica o papel dos anjos tanto na formação de novas empresas, quanto para efetuar mudanças importantes em uma empresa já existente. Esse tipo de financiamento provém de profissionais que desejam investir parte de suas reservas em pessoas que conheçam. O desenvolvimento empreendedor pode depender desse tipo de financiamento no começo, pois usualmente as pessoas físicas quando emprestam dinheiro tendem a ser mais tolerantes que as pessoas jurídicas quanto ao retorno.

A preocupação com a interpretação do meio para se posicionar quanto aos tipos de financiamento é importante, pois para Baron e Shane (2007) a arrecadação de fundos para a atividade empreendedora pode se tornar difícil devido às assimetrias de informações e à incerteza de que o negócio irá prosperar por parte dos agentes financiadores. No meio podem existir vários agentes de apoio como bancos, cooperativas, financeiras, financiamento por anjos, entre outros agentes.

Outro recurso contido no meio diz respeito aos recursos imateriais que representam a formação e a informação, facilitando a compreensão do ambiente para que empreendedores consigam se posicionar frente a uma mudança. Um exemplo desses recursos pode ser a divulgação de informações capazes de reduzir a incerteza do ambiente ao estimular o intercambio de conhecimento entre os agentes. O meio oferece, segundo Julien (2010), cinco tipos de proximidade existentes na sociedade: a proximidade cognitiva (compartilhamento de conhecimentos comuns), proximidade organizacional (favorece as relações internas e externas), proximidade sociocultural (rede de relações pessoais, compartilhamento de valores, normas e convenções), proximidade institucional (leis e normas institucionais) e proximidade geográfica (facilita os encontros não oficiais para obter recursos de base).

Como os elementos estão inseridos no ambiente, a análise de tal ambiente deve ser criteriosa, abordando aspectos econômicos, infraestrutura, políticos, entre outros. Assim a classificação dos elementos em dimensões torna a análise mais consistente, facilitando a avaliação do empreendedor em suas regiões de atuação.

\section{ASPECTOS COGNITIVOS, NORMATIVOS E REGULATIVOS}

As variáveis do ambiente podem ser interpretadas com os seguintes parâmetros: cognitivo, normativo e regulativo. A intenção é compreender, por meio das referidas dimensões, como as variáveis podem influenciar no desenvolvimento das regiões.

A regulamentação enquanto dimensão consiste em leis, regulamentos e políticas governamentais que dão subsídios aos novos negócios, reduzindo os riscos de inicialização de uma nova organização e facilita na obtenção de recursos para os empreendedores. As instituições podem influenciar por meio dos recursos que 
são disponibilizados através de programas de patrocínio governamental, privilégios decorrentes de políticas públicas que incentivam a criação de micro e pequenas empresas (RONDINELLI; KASARDA, 1992).

A questão é que a dimensão regulativa é capaz de conduzir o regramento da sociedade e garantir o direito de propriedade das organizações. Isso porque as instituições são legitimadas pelos agentes (SCOTT, 1995) e garantem o "enforcement" (fazer valer) condizente para o desenvolvimento do comercio.

A dimensão cognitiva consiste no conhecimento e habilidades das pessoas em um determinado ambiente, mas o conhecimento proposto nessa dimensão são aqueles pertinentes para estabelecer e operar um novo negócio. O conhecimento conjunto contribui para a disseminação do conhecimento entre os agentes do segmento (BUSENITZ; BARNEY, 1997).

Quando os integrantes do meio não têm o costume de divulgar as informações, ou seja, praticar a sinalização de suas ações no mercado, algumas pessoas podem sentir a falta de conhecimento necessário para compreender mesmo as mais básicas etapas requeridas para iniciar e gerir um pequeno negócio.

A dimensão normativa mede o grau pelo qual os moradores de um país admiram a atividade empreendedora, valorizando a criatividade e a inovação. Alguns pesquisadores como Knight (1997) tem argumentado que a cultura de um país, valores, crenças e normas afetam a orientação empreendedora de seus moradores. Em regiões em que os empreendedores tiveram sucesso com suas empresas, o resultado é uma valorização da atividade empreendedora atuando como uma potência. Para confirmar as preposições, Casson (1990) argumenta que em alguns sistemas de valor, os empreendedores são admirados por sua criatividade e iniciativa, mas em outros ambientes eles não são, isso depende da cultura e dos sucessos anteriores.

As dimensões podem ser estudadas como ferramentas que facilitam a compreensão do crescimento ou inibição do crescimento empreendedor, ou ainda, quais os segmentos da economia que teriam um alto potencial de sucesso devido à concentração de elementos favoráveis ao ramo em determinada região. $\mathrm{O}$ capital social, existente ou fomentado em determinada região, constitui o elemento do meio que favorece as transformações e por isso será comentado a seguir.

\section{CAPITAL SOCIAL}

O capital social é um dos elementos-chave do desenvolvimento das atividades empreendedoras, além de recursos financeiros, o capital social fornece ao empreendedor modelos (representações) que auxiliam na criação de novas empresas. O empreendedor obtém informações e conhecimento no meio através de laços, relações e interações com o segmento industrial que pertence. Para Julien (2010) as redes de reconhecimento social podem ser limitadoras, mas também podem ser estimulantes. Nessa perspectiva, as redes podem incluir ou excluir as oportunidades do empreendedor, pois o meio está modelado de uma forma a impulsionar e capacitar a sociedade.

Para Prashantham e Dhanaraj (2010), o capital social é capaz de facilitar a entrada dos empreendedores nos mercados, por fornecer vantagens que se estivesse operando no mercado por conta própria não as teria. Isso demonstra o potencial de melhorias que o capital social pode oferecer a um empreendedor que deseja se lançar no segmento. 
As necessidades do empreendedor podem ser atendidas, mas ele deve se preocupar com sua reputação ao longo dos anos para retribuir os benefícios que usufruiu com o capital social, é fundamental que o empreendedor crie valor com suas atividades para que outros consigam aproveitar o seu legado para a região progredir.

É uma espécie de rodízio de informações que necessita receber um feedback para progredir. Segundo Jack (2005) da mesma forma que uma empresa evolui e precisa se renovar, os relacionamentos também precisam se transformar em uma espécie de ciclo de vida, sem romper com o seu meio.

A essência do capital social é que a rede de relacionamento do empreendedor como família, amigos, encontros casuais, conversas com estranhos, pode proporcionar uma riqueza em termos de conhecimento, informação e até mesmo apoio para continuar, caso o payback demore a ocorrer (TAYLOR, et al, 2004).

\section{A INFLUÊNCIA DAS DIMENSÕES COGNITIVA, NORMATIVA E REGULATIVA NOS ELEMENTOS DO “MEIO"}

Da mesma forma que North (1991) explicou o desenvolvimento das instituições fazendo um paralelo com o desenvolvimento econômico dos países, é possível imaginar o desenvolvimento de uma região considerando o seu interesse e evolução pelos elementos de caráter normativo, regulativo e cognitivo.

Quando se fala em desempenho regional, a tendência é pensar nos elementos do meio que se enquadram na dimensão normativa que consistem em leis, regulamentos e políticas governamentais que dão subsídios aos novos negócios. No entanto, as demais dimensões influenciam no desenvolvimento das atividades empreendedoras, a prova desse fato seria a expressão "estar sempre alerta" que se utiliza na identificação de oportunidades.

Como um empreendedor poderia realizar a identificação de oportunidades se não tivesse informações suficientes para trabalhar com a dimensão cognitiva? O complemento das dimensões é uma sinergia de elementos que propiciam o desenvolvimento empreendedor, acarretando no desenvolvimento regional caso essa mesma região seja capaz de dar subsídios para o referido empreendedor.

Ao longo da revisão das teorias foram identificados elementos do meio com alto potencial de influência do desempenho regional, partindo do pressuposto de que o empreendedor utiliza dos recursos do ambiente para atuar no mercado, recolhendo informações, processando-as e criando valor. Para uma melhor compreensão é possível catalogar os principais elementos que destacamos no presente trabalho segundo as três dimensões propostas por Busenitz et al. (2000).

Um ponto que chama a atenção, no Quadro 1, é que alguns elementos do meio quando analisados como instituições são classificados como de caráter normativo, no entanto quando os efeitos de segunda ordem são apurados é possível perceber uma miscigenação de dimensões, ou seja, a influencia mútua das dimensões. Um exemplo dessa integração são as Universidades que podem ser enquadradas como "normativas" em T1, mas o efeito causado em seus alunos em T2 (proporcionando o livre pensar, capacitando, criando habilidades) é catalogado como na esfera Cognitiva. 
QUADRO 1- Elementos do meio e as dimensões regulativa, normativa e cognitiva

\begin{tabular}{|c|c|c|c|}
\hline & REGULATIVA & NORMATIVA & COGNITIVA \\
\hline \multirow{4}{*}{ ELEMENTOS DO MEIO } & Leis & Cultura & Conhecimento \\
\cline { 2 - 4 } & Regulamentos & Valores/ Crenças & Habilidades \\
\cline { 2 - 4 } & Políticas governamentais & Escola/Universidades & Conhecimento conjunto \\
\cline { 2 - 4 } & Estatutos & Normas & Redes de informação \\
\cline { 2 - 4 } & Atas & Parcerias & Técnicas \\
\cline { 2 - 4 } & Planos de desenvolvimento & Confiança & Capacidades \\
\cline { 2 - 4 } & Infraestrutura & Família & Know-How \\
\hline
\end{tabular}

Fonte: Adaptado de Gartner (1975, p. 702)

Isso demonstra o potencial de influência que as dimensões possuem no ambiente. Do mesmo modo, em um primeiro momento o governo pode criar políticas governamentais (regulativa) para fomentar o desenvolvimento de escolas e universidades (normativa) que por sua vez irá capacitar as pessoas de determinada região (cognitiva).

É possível então explicar as diferenças entre as regiões, ainda que parcialmente, pelos recursos e capacidades que uma região possui. A grande dificuldade é administrar os recursos do ambiente para que tenham poder de influência no mercado. Cada elo da cadeia produtiva possui obrigações no que diz respeito a criar regras, regulamentos, instituições e até mesmo informações para que os outros agentes consigam absorver as informações e criar valor em sua atividade.

O empreendedor estaria, dessa forma, lidando com todos os elementos simultaneamente, pois estaria no centro de uma série de fatores que podem influenciar positiva ou negativamente o meio em que o empreendedor está atuando. A intersecção das dimensões, pode ser visualizada na figura 1.

Figura 1 - A posição do empreendedor com as dimensões do meio

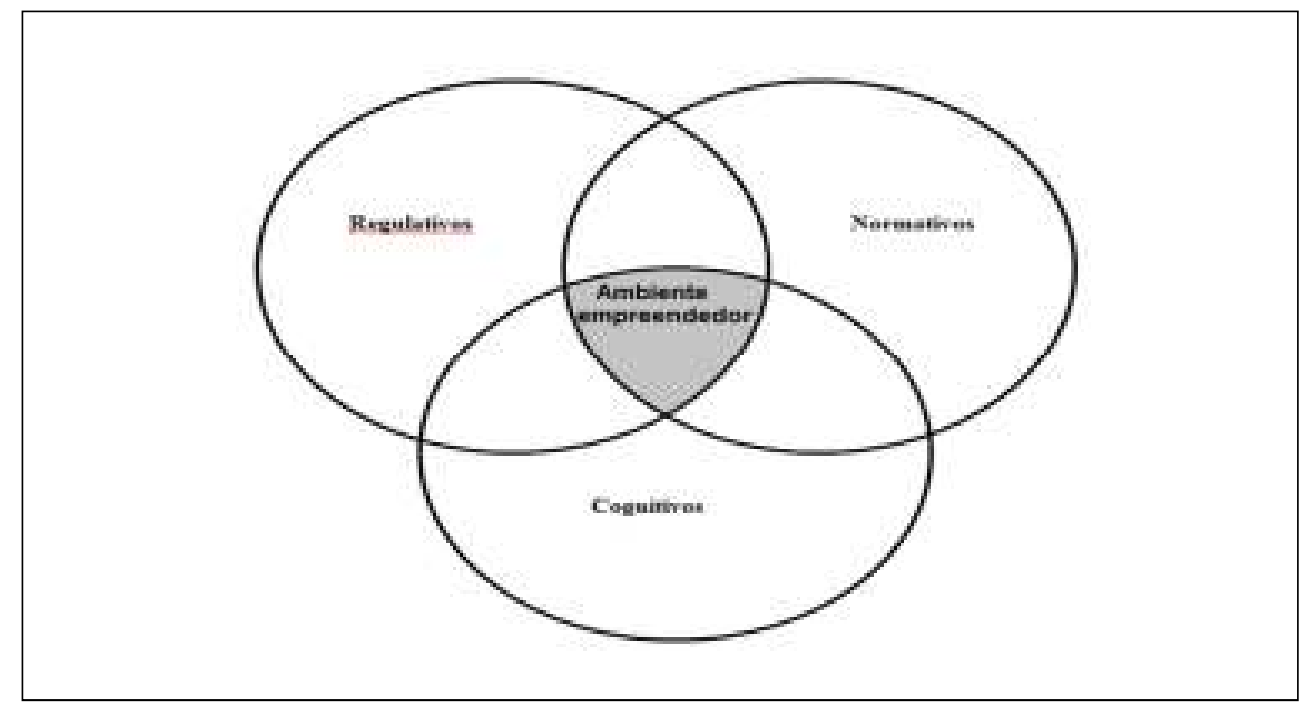

Fonte: Elaborada pelos autores.

De acordo com a Figura 1, o empreendedor estaria em um plano, considerado meio, e circunscrito de elementos que são classificados em três dimensões, Normativa, Cognitiva e Regulativa. O empreendedor está envolto a elementos que influenciam diretamente as suas atividades, assim é imprescindível que o empreendedor possua informações e saiba conduzi-las para conseguir lidar com todas as forças do ambiente.

O empreendedor está presente em todo o conjunto, no entanto, há uma maior intensidade da sua presença na área destacada da Figura 1. Esse destaque ocorre devido à concentração simultânea de 
elementos pertencentes às três dimensões do meio, então é possível denominar essa área como "ambiente empreendedor". O ambiente empreendedor é formado pela presença constante de elementos normativos, cognitivos e regulativos em determinado meio, a condição de existência é que tais elementos estejam à disposição dos empreendedores e que consigam criar uma sinergia capaz de contribuir com o fomento do empreendedorismo.

Ao reconhecer que todos os elementos pertencem a um mesmo plano (meio), é natural que existam elementos comuns entre os conjuntos (dimensões), por exemplo, quando as leis são criadas pertencem a um montante de elementos do conjunto Regulativo, mas com a progressão do tempo os efeitos daquele elemento podem ser remanejados para o conjunto Normativo. Com isso, os elementos são dependentes do fator tempo para mover os elementos entre os conjuntos. Assim, cada dimensão contribui para a formação do "ambiente empreendedor".

\section{Dimensão Regulativa}

A interação entre os agentes em um contexto econômico pode propiciar o desenvolvimento do ambiente empreendedor com o auxílio de um meio repleto de subsídios. Dentre os agentes, um ganha destaque por ter um papel diferenciado dos demais: o Estado. Para Shane (2003), as mudanças nas políticas voltadas ao empreendedorismo oferecem a possibilidade para que as pessoas realoquem recursos para um novo uso, de forma que este se torne mais produtivo.

No entanto a realocação de um recurso para uma nova utilização depende do conhecimento adquirido com sua experiência, estudos e trocas de informação. Em uma sociedade que tem o costume de cambiar conhecimento, a admiração do empreendedorismo pode ser aguçada, favorecendo o aprendizado e as habilidades.

O clima regulamentar em um estado afeta a capacidade de um empreendedor para fazer o seu negócio crescer. Embora as políticas sejam formuladas no âmbito federal, Taylor et al (2004) defendem que os líderes regionais podem pressionar o governo a fim de serem beneficiados com políticas condizentes com suas atividades. Portanto, algumas regiões podem gerar um número maior de start-ups devido à efetiva participação do governo na criação de políticas favoráveis ao desenvolvimento do empreendedorismo.

No que diz respeito à tecnologia, Hisrich e Peters (2004) defendem que o setor público desempenha um papel de grande responsabilidade para o fomento às atividades empreendedoras. Talvez o ponto-chave para compreender o papel do Estado em determinados segmentos seja o aporte financeiro necessário para quebrar as barreiras de entrada. Para realizar uma atividade base, ou desenvolver pesquisas que irão gerar novas tecnologias no futuro é necessário grande montante financeiro, capital esse que os novos empreendedores usualmente não possuem.

Da mesma forma que Machado (2001) discute reduções de obstáculos para a criação de oportunidades para as mulheres empreenderem caso houvesse uma adoção de políticas públicas destinadas ao empreendedorismo feminino, as políticas governamentais como um todo poderiam ser de grande interesse público, em especial aos empreendedores, por fornecerem condições para que novas etapas e valores sejam criados. 
Para Silva e Machado (2008) a existência de um ambiente propício ao empreendedorismo pode ser construída. Isso não significa que o empreendedorismo não apareça fora do ambiente empreendedor, mas em regiões com maior participação do governo, as influências favoráveis tendem a se desenvolver mais.

Para Taylor et al (2004) o elemento-chave de produção do conhecimento é que ela ocorre como um resultado da interação entre teoria e prática. Reconhecendo a dimensão Regulativa, as atividades do ambiente podem contar com uma sinergia entre as qualidades, valores e regulações que servem como complemento às demais atividades.

\section{Dimensão Normativa}

O pressuposto para compreender o campo normativo é assumir o seu caráter de longo prazo. Um típico exemplo dessa dimensão seria cultura, formada há muitos anos e que a cada novo integrante é moldada através da contribuição ou incremento de sua vivência. É através da cultura que os demais elementos do meio surgem, principalmente quando se trata de valores e crenças compartilhadas. Não adianta iniciar uma discussão dos desenvolvimentos empreendedores sem considerar a cultura do povo, pois as instituições existem através da legitimação. Assim, uma região pode se desenvolver devido às ações de um povo que por sua vez é guiado por sua cultura.

Outro ponto em destaque da dimensão normativa é a presença da família na construção do ambiente empreendedor, pois no início o apoio é fundamental para que o empreendedor continue com suas atividades mesmo passando por dificuldades. Dependendo do sentido que a família exerce em determinada cultura, os agentes podem também se amparar financeiramente na familia.

Taylor et al (2004) fazem menção ao tratamento dado aos stakeholders do seu negócio, pois o modo como trata os clientes e fornecedores pode ser herdado pela cultura de um povo. Além do suporte inicial que a dimensão normativa pode oferecer, ainda é possível pensar no desenvolvimento desses relacionamentos, pois em um segundo momento as pessoas que perceberam ou se identificaram com o tratamento dado pelo empreendedor podem, em um segundo momento, gerar uma admiração pelo empreendedorismo, facilitando os laços de confiança e fidelidade ao longo dos anos.

A sustentação da confiança regrada pelos relacionamentos ao longo dos anos abre margem ao desenvolvimento da criatividade e iniciativa dos empreendedores. Assim pode-se dizer que em ambientes cuja confiança é bem alicerçada, o potencial inovador dos empreendedores tende a ser maior. Outro efeito de segunda ordem advindo dessa confiança é a redução de custos para se trabalhar via mercado, ou conseguir novos "anjos" para o financiamento de novos empreendimentos. Ou seja, através do desenvolvimento de um conjunto de elementos de cunho normativo, uma região pode se beneficiar em termos financeiros e até mesmo sobre o desenvolvimento do empreendedorismo pela prática de relacionamentos sustentáveis. 


\section{Dimensão Cognitiva}

Por fim, a dimensão cognitiva, assim como as demais, pode beneficiar o desenvolvimento do ambiente empreendedor através das capacidades adquiridas pelo empreendedor e que serão necessárias para operacionalizar as suas ideias.

Politis (2005) argumenta que embora algumas informações e conhecimento possam ser aprendidas através da educação, grande parte das informações necessárias para aproveitar uma oportunidade é obtida com a prática. Nesse ponto há duas questões fundamentais para analisar. A primeira diz respeito à abertura do aprendizado empreendedor que o autor enfatiza, pois se partirmos do pressuposto de que o empreendedor pode aprender com o tempo como precisa operar para se tornar um empreendedor, a dimensão cognitiva se fortalece fomentando a educação. O segundo ponto é a prática do empreendedorismo como fonte de conhecimento e desenvolvimento. Através da prática empreendedora, as redes de informações são ativadas, propiciando uma alavancagem na qualidade das informações.

Todos os itens cognitivos focam sobre a consciência de sucesso empreendedor e o conhecimento do público para aproveitar uma nova oportunidade no mercado. Os agentes da sociedade podem se inspirar nos atuais empreendedores e aceitar que abrir uma empresa seria trilhar uma carreira de sucesso.

\section{TRABALHOS SOBRE A TEMÁTICA}

Grégoire, Corbett e McMullen (2011) avaliaram o estado do campo científico em pesquisa relacionadas a cognição e o empreendedorismo, com uma análise de conteúdo em publicações entre 1976 e 2008. A pesquisa sobre empreendedorismo e cognição não produziu recursos conceituais principais totalmente articulados do ponto de vista cognitivo. Com base nestas observações, foram propostas estratégias concretas e questões de pesquisa para aumentar a contribuição da investigação do aspecto cognitivo no empreendedorismo, e avançar essa investigação para além do seu foco atual em "consequências cognitivas". Em particular, ilustram o potencial acadêmico de desembaraçar os vários antecedentes de empreendedorismo e cognição, de estudar as interações entre processos entre recursos cognitivos e representações mentais e de explorar o funcionamento do empreendedorismo e a cognição entre os diferentes níveis de análise.

Fini e Toschi (2015), ao focarem o contexto em que são estabelecidas novas empresas, estudaram a medida em que as intenções empresariais corporativas são encenadas de forma diferente por empreendedores acadêmicos e não acadêmicos. Usando construções de pesquisa cognitiva e explorando a teoria das lógicas institucionais, observaram que os empreendedores acadêmicos, não obstante o seu envolvimento no empreendedorismo, ainda implementam suas intenções empreendedoras corporativas deliberando de acordo com o ambiente institucional acadêmico a que pertencem. Usando um projeto de pesquisa de pares combinados, os resultados mostram que os empreendedores acadêmicos (em comparação com os não-acadêmicos) alavancam mais a sua consciência de competências técnicas e menos sua auto-eficácia empresarial e conscientização das competências de gestão. Na pesquisa ainda são discutidas as implicações teóricas e gerenciais relacionadas a como o aspecto cognitivo e os fatores institucionais interagem para promover valores empresariais em empresas recentemente criadas. 
Urbano e Alvarez (2014) analisaram a influência das dimensões institucionais (regulativos, normativos e cultural-cognitivos) sobre a probabilidade de se tornar um empreendedor. Os principais resultados demonstram, por meio de regressão logística, que a dimensão reguladora favorável (menos procedimentos para abrir uma empresa), dimensão normativa (maior atenção da mídia para novos negócios) e dimensão cultural-cognitiva (melhores competências empresariais, menos medo do insucesso empresarial e melhor conhecimento técnico de empresários) aumentam a probabilidade de ser um empreendedor. Os dados foram obtidos a partir de uma amostra de 36.525 indivíduos de 30 países. O estudo avança a literatura, fornecendo novas informações sobre os fatores ambientais que afetam a atividade empreendedora, à luz da economia institucional.

Knorr, Alvarez e Urbano (2013) analisaram a influência da dimensão cultural-cognitiva, medida através da criatividade, tomada de risco e independência - sobre a probabilidade de se tornar um empreendedor ou um empregado. Os dados foram obtidos a partir de uma amostra de 41 países e 56.875 indivíduos. Os principais resultados demonstram que a criatividade, a assunção de riscos e independência aumentam a probabilidade de se tornar empresário, e diminuem a probabilidade de se tornar empregado. Dado que estas características facilitam o nascimento de novas ideias, processos, produtos e serviços, é crucial para aprender com os empresários e fomentar essas características dentro das organizações.

Kibler e Kautonen (2014) examinaram a influência da legitimidade moral dos empresários sobre o envolvimento de um indivíduo em empreendedorismo em estágio inicial. A análise multinível conduzida em 26 países demonstrou que quanto maior a percepção do grau de legitimidade moral, mais provável é que um indivíduo considere iniciar um negócio. As normas morais na sociedade são uma influência importante sobre início da carreira empreendedora.

Estes estudos, são alguns exemplos de utilização de variáveis que podem influenciar o meio empreendedor ou não e, de certa forma, dão subsídios para a criação de uma agenda de pesquisa no campo científico, seja para a definição de novos indicadores isolados que possam vir a influenciar o meio empreendedor, seja pela correlação dos aspectos normativo, cognitivo e regulatório do meio. De qualquer forma, são novas questões e dimensões que podem ser investigadas a fim de auxiliar, na prática, a atividade empreendedora.

\section{CONSIDERAÇÕES FINAIS}

A análise do meio e seus elementos utilizando as dimensões propostas (cognitiva, regulativa e normativa) proporcionou uma visão detalhada sobre os elementos do ambiente. Embora pareçam distintos, todos estão conectados direta ou indiretamente, basta considerar o fator tempo na análise. Com uma análise de curto prazo, pode-se visualizar apenas a criação de algum programa, política, estatuto, mas se fizer uma análise de longo prazo, é possível perceber que as políticas criadas no passado podem condicionar o conhecimento dos agentes no presente e futuro.

Ocorre uma retroalimentação dos elementos, inicialmente um programa de fomento ao desenvolvimento empreendedor é criado, em seguida as habilidades de uma região podem ser potencialmente desenvolvidas, podendo motivar a procura do povo por escolas e universidades em busca de informações para atuar no mercado. Essa busca de conhecimento pode estar ligada a uma rede de amigos 
ou de informações capazes de disseminar o conhecimento e know-how para seus participantes. Assim, quando os conhecimentos são validados com a prática, pode ocorrer o reconhecimento da sociedade, ao admirar e reconhecer que as atividades empreendedoras são válidas.

Esse reconhecimento da população gera uma massa pensante que anseia por mudanças e desenvolvimentos institucionais que apenas o Estado pode fornecer, criando então novas discussões para a geração de programas, desenvolvimento de leis, infraestrutura, entre outros elementos do meio que são categorizados como "regulativos" mas que impactam em todos os elos da sociedade.

Assim o objetivo do artigo [identificar como estudos contemporâneos consideram o meio e como atividades empreendedoras são influenciadas, levando-se em conta os elementos normativo, regulativo e cognitivo, a fim de identificar os aspectos do ambiente que influenciam a atividade empreendedora] foi atingido. Da mesma forma, o pressuposto inicial de que o meio poderia influenciar diretamente os empreendedores que nele trabalham, foi confirmado.

A compreensão da complementaridade dos elementos do meio é relevante para os estudos em empreendedorismo, pois com ela, futuras mudanças no meio podem ser melhor interpretadas, reconhecendo o seu grau de impacto nos demais itens do meio. Os diferentes elementos do ambiente podem ser capazes de explicar as diferenças entre uma região e outra no que diz respeito ao número de empreendedores, número de empresas abertas, quantidade de instituições financeiras, entre outros elementos que impulsionam a economia e consequentemente o empreendedorismo.

No entanto, vale salientar que cada região tem suas especificidades, ou seja, os elementos do meio quando estudado com as três dimensões são únicos, cada região se comporta de uma forma. As abordagens do meio devem ser analisadas em loco demandando tempo e uma investigação precisa nas variáveis. Em pesquisas futuras, pesquisadores poderiam realizar estudos para confirmar ou negar as afirmações feitas neste trabalho. Poderiam aplicar pesquisas em cidades que replicam as grandes capitais, para identificar pontos fortes e fracos da sua política e desenvolvimento.

Assim o argumento defendido por Julien (2010) de que o meio é mais do que os elementos que o constitui é verdadeira, pois a interação dos agentes acarreta em uma sinergia no mercado capaz de estimular as trocas de informações, relacionamentos de confiança e criação de regramentos que impulsionam as atividades empreendedoras. Ao integrar as teorias que circunscrevem o "meio" e o empreendedorismo através das dimensões propostas neste artigo, demonstra que a interação entre os elementos do meio se constituem mais um fator influenciador do "ambiente empreendedor".

Para o empreendedorismo, ponderar a importância do meio como propulsor do desenvolvimento empreendedor, e ainda, classificar os elementos do meio em dimensões gera uma série de novas implicações para o campo, pois compreender a formação dos elementos através do tempo gera novas estratégias para o fomento do empreendedorismo. O estudo de regiões tornou-se importante para a mensuração da potencialidade das ideias, considerando leis, estatudos, culturas, universidades, conhecimento, entre outros elementos do meio considerados relevantes para o desenvolvimento empreendedor.

A compreensão das características de uma região, considerando a presença intensa dos elementos cognitivos, normativos e regulativos, proporciona uma avaliação com propriedade do meio. Essa compreensão é aprofundada com a delimitação do ambiente empreendedor, aumentando a possibilidade de existir condições favoráveis aos empreendedores. Ao classificar os elementos do meio em dimensões, novos 
parâmetros de análise são criados, mantendo o número de instituições em determinada região e realizar um estudo longitudinal, ou seja, explorar o fator tempo em determinada região. Ou ainda, estudar uma região que, em década passada, aumentou o número de universidades e escolas (dimensão normativa) para identificar melhorias no potencial empreendedor dessa região/cidade.

A implicação da interpretação dos elementos do meio ou ainda do ambiente empreendedor, permite que novas interpretações do empreendedorismo sejam criadas, incentivando e desenvolvendo instituições que promovam o desenvolvimento empreendedor em diferentes áreas de negócios.

\section{REFERÊNCIAS}

ARMINGTON, Catherine; ACS, Zoltan J. The determinants of regional variation in new firm formation. Regional studies, v. 36, n. 1, p. 33-45, 2002.

BAGNASCO, A. Teoria del captale sociale e political economy comparata. Stato e Mercato, n.3, p. 351-372, 1999.

BARON, R. A.; SHANE, S. A. Empreendedorismo: uma visão do processo. Trad. All Tasks. São Paulo: Thompson Learning, 2007.

BUSENITZ, L. W.; BARNEY, J. B. Differences between entrepreneurs and managers in large organizations: biases and heuristics in strategic decision-making. Journal of Business Venturing, New York, v. 12, p. 9-30. 1997.

BUSENITZ, L. W.; GÓMEZ, C.; SPENCER, J. W. Country institutional profiles: unlocking entrepreneurial phenomena. Academy of Management Journal. v. 43, n. 5, p. 994-1003, oct. 2000.

CAMAGNI, R. Development scenarios and policy guideline for the lagging regions in the 1990s. Regional Studies, v. 26, n.4, p. 361-374, 1991.

CASSON, M. Enterprise and competitiveness. Nova York: Oxford University Press, 1990.

FELDMAN, Maryann P. The entrepreneurial event revisited: firm formation in a regional context. Industrial and corporate change, v. 10, n. 4, p. 861-891, 2001.

FINI, Riccardo; TOSCHI, Laura. Academic Logic and Corporate Entrepreneurial Intentions: A Study of the Interaction between Cognitive and Institutional Factors in New Firms. Available at SSRN 2562797, 2015.

GARTNER, W. B. A conceptual framework for describing the phenomenon of new venture creation. Academy of management review. v. 10, n. 4, p. 596-708, oct. 1975.

GRÉGOIRE, Denis A.; CORBETT, Andrew C.; MCMULLEN, Jeffery S. The cognitive perspective in entrepreneurship: an agenda for future research..Journal of Management Studies, v. 48, n. 6, p. 1443-1477, 2011.

HAGUETTE, T. M. F. Metodologias qualitativas na sociologia. Petrópolis: Vozes, 2001.

HAGUETTE, Teresa Maria Frota. Metodologias qualitativas na sociologia. 2001.

HISRICH, R. D; PETERS, M. P. Empreendedorismo. Trad. Lene Belon Ribeiro. 5.ed. Porto Alegre: Bookman, 2004.

JACK, S. L. The role, use and activation of strong and weak ties: a qualitative analysis. Journal of Management Studies. v. 42, n. 6, p. 1233-1259, sep. 2005.

JANSSEN, F. Does the environment influence the employment growth of SMEs?. Journal of Small Business and Entrepreneurship. v. 22, p. 311-326, 2009.

JENSEN, M.C.;MECKLING, W.H. Theory of the firm: managerial behavior agency costs and ownership structure. Journal of Financial Economics, v.3, n.4, p. 305-360, 1976.

JULIEN, P.A. Empreendedorismo regional e a economia do conhecimento. São Paulo: Saraiva, 2010.

KIBLER, Ewald; KAUTONEN, Teemu. The moral legitimacy of entrepreneurs: An analysis of early-stage entrepreneurship across 26 countries. International Small Business Journal, p. 0266242614541844, 2014.

KNIGHT, G. A. Cross-cultural reliability and validity of a scale to measure firm entrepreneurial orientation: Journal of Business Venturing. v. 12, n. 3, p. 213-225, may 1997.

KNÖRR, Helena; ALVAREZ, Claudia; URBANO, David. Entrepreneurs or employees: a cross-cultural cognitive analysis. International Entrepreneurship and Management Journal, v. 9, n. 2, p. 273-294, 2013.

KOSTOVA, Tatiana. Transnational transfer of strategic organizational practices: A contextual perspective. Academy of management review, v. 24, n. 2, p. 308-324, 1999.

KURATKO, D. F.; HODGETTS, R. M. Entrepreneurship: a contemporary approach. 5.ed. Orlando: Harcourt, 2001. 
LICHTENSTEIN, Gregg A.; LYONS, Thomas S. The entrepreneurial development system: Transforming business talent and community economies. Economic Development Quarterly, v. 15, n. 1, p. 3-20, 2001.

MACHADO, H. P. V. Empreendedorismo, gênero e políticas públicas. In: EGEPE - ENCONTRO DE ESTUDOS SOBRE EMPREENDEDORISMO E GESTÃO DE PEQUENAS EMPRESAS, 2., 2001, Londrina. Anais... Londrina: UEM/UEL, 2003. 1 CD-ROM, 378-393.

MUELLER, S. L.; THOMAS, A. S. Culture and entrepreneurial potential: a nine country study of locus of control and innovativeness. Journal of Business Venturing. v. 16, n. 1, p. 51-75, jan. 2000.

NORTH, D. C. Institutions. Journal of Economic Perspectives. v. 5, n. 1, p. 97-112, Winter 1991.

POLITIS, D. The process of entrepreneurial learning: a conceptual framework. Entrepreneurship Theory and Practice. v. 29, n. 4, p. 399-424, jul 2005.

PRASHANTHAM, S.; DHANARAJ, C. The dynamic influence of social capital on the international growth of new ventures. Journal of Management Studies. v. 47, p. 967-994, feb. 2010.

RATTI, R.; BRAMANTI, A.; GORDON, R. The dynamics of innovative regions. Adelshot: Ashgate, 1997.

RONDINELLI, D. A.; KASARDA, J. D. Foreign trade potential, small enterprise development and job creation in developing countries. Journal Small Business economics. v. 4, p. 253-265, nov. 1992.

SCOTT, W. R. Institutions and Organizations. London: Sage Publications. 1995.

SHANE, S. A. A general theory of entrepreneurship: the individual-opportunity nexus. Massachusetts: Ed. Edward Elgar Publishing Inc., 2003.

SILVA, J. M. da; MACHADO, H. P. V. Empreendedorismo e políticas públicas em pequenos municípios paranaenses: interpretações, participações e desdobramentos. Revista Pretexto. v. 9, n. 4, p. 9-32, out. 2008.

TAYLOR, D. W.; JONES, O.; BOLES, K. Building social capital through action learning: an insight into the entrepreneur. Journal of small business and enterprise development. v. 46, n. 5, p. 226-235. 2004.

TAYLOR, J. S. What makes a region entrepreneurial?: a review of the literature. Center for Economic Development, Maxine Goodman Levin College of Urban Affairs. Cleveland State University, p. 1-21, sep. 2006.

URBANO, David; ALVAREZ, Claudia. Institutional dimensions and entrepreneurial activity: an international study. Small Business Economics, v. 42, n. 4, p. 703-716, 2014.

VAZ, M. T. de N. Desenvolvimento regional e inovação empresarial: o impacto do desenvolvimento local nas determinantes de inovação das pequenas empresas. Revista paranaense de desenvolvimento. Curitiba, v.108, p. 7-24, jan. 2005. 